\title{
Bóvedas de madera: características constructivas y consideraciones estructurales de las bóvedas encamonadas edificadas en Castilla
}

\author{
Wooden vaults: construction characteristics and structural \\ considerations of the planked timber vaults built in Castile
}

$\underline{\text { P. Hurtado }}^{(*)}$

RESUMEN

A finales del siglo XVI hacen su aparición en Castilla las técnicas encamonadas para la ejecución de cúpulas y bóvedas. En los dos siglos venideros innumerables bóvedas encamonadas se levantarán en tierras castellanas. Muchas de estas construcciones se perderían posteriormente, como consecuencia de incendios, guerras e incluso restauraciones que las eliminaron con el argumento de dejar a la vista armaduras de mayor antigüedad. El presente trabajo trata de mostrar las características constructivas de estas bóvedas a partir de su descripción en tratados de arquitectura, documentos de archivo y casos concretos observados. Se pretende además establecer consideraciones para el estudio de su comportamiento estructural.

850-15

Palabras clave: Bóveda; encamonada; construcción; madera; estructura.

\section{SUMMARY}

In the late sixteenth century made their appearance in Castile the planked timber techniques for building domes and vaults. In the two centuries to come it will build innumerable planked timber vaults in Castile. Many of these were subsequently lost as a result of fires, wars and even restorations that removed them, leaving another wooden roof of greater antiquity. This paper tries to show the construction characteristics of these vaults from the perspective of their descriptions in archival documents, architectural treatises and cases observed. It also aims to establish considerations for studying their structural behaviour.

Keywords: Vault; planked timber; construction; wood; structure. 
1a. Traza de Francisco de Moradillo elaborado en 1745 para la cúpula de la capilla de San Idelfonso en Alcalá de Henares.

1b. Cúpula de la iglesia de San Juan de la Penitenciaría durante su restauración.

1c. Exterior de la cúpula una vez terminada su restauración.

\section{INTRODUCCIÓN}

A mediados del siglo XVI el arquitecto francés Philibert De L'Orme planteó la posibilidad de cubrir grandes espacios con una sucesión de arcos de madera unidos con correas pasantes, consiguiendo con ello la definición de una bóveda. Estos arcos se conformaban con camones y contracamones, que eran tablas curvas de similares dimensiones, colocados contrapeados entre si. Extrañamente los tratadistas españoles de esta centuria no comentaron la propuesta de De L'Orme, a pesar que él mismo mencionó que su obra circulaba en España (1). Incluso en el siglo siguiente sólo se tiene la anecdótica mención de Juan de Torija, quien paradójicamente aprovechó el texto del arquitecto galo como apoyo para la elaboración de su propio tratado. Sin duda Torija se detuvo a analizar la experiencia De L'Orme en lo concerniente a la estereotomía de la piedra y a la ejecución de bóvedas con este material, pero no dedicó capítulo alguno a las bóvedas encamonadas (2).

Conviene precisar que en 1578 Nicolás de Vergara El Mozo durante la reconstrucción de la iglesia de Santo Domingo El Antiguo en Toledo, bajo proyecto de Juan de Herrera, señaló que se debían incluir arcos encamonados en la armadura de la cúpula (3). Esta traza incorporaba una media naranja en base a un sistema de ochos grandes arcos de madera formados por camones para cubrir el cuerpo octogonal del crucero. Efectivamente la disposición de los arcos sobre una planta poligonal, que buscaba recrear el efecto de una cúpula, identificó a las armaduras encamonadas castellanas y posiblemente fue el inicio del uso de esta técnica en España. Contrariamente Fray Lorenzo de San Nicolás manifestó que fue el jesuita Francisco Bautista el primero en utilizar este tipo de cúpula en la iglesia del Colegio Imperial de San Isidro, en Madrid a comienzos del siglo XVII. Aunque el arco formado con camones como elemento constructivo para armar cúpulas de madera era ya conocido en Castilla antes de aquella fecha (4).

\section{LAS BÓVEDAS ENCAMONADAS EN CASTILLA}

La eclosión constructiva de las bóvedas encamonadas se produjo principalmente en tierras castellanas, como en su época lo comentó San Nicolás en referencia a las ciudades de Madrid, Salamanca y Talavera La Reina. Sin embargo estas armaduras muestran en realidad una mayor proximidad a los chapiteles con un perfil exterior curvo. En efecto, la cúpula encamonada castellana se caracterizó por ser una estructura conformada por piezas rectas dispuestas sobre una planta poligonal, dejando a los arcos de madera solamente la definición del contorno curvo de la cubierta. Esto se hace evidente en la cúpula de la capilla de San Juan de la Penitenciaría y en el proyecto no efectuado de Francisco de Moradillo en 1745 para la cúpula de la capilla de San Ildefonso, ambos en Alcalá de Henares. Estas cúpulas presentan características constructivas reflejadas por San Nicolás y Rodrigo Álvarez en sus respectivos tratados para el caso de chapiteles (Figuras $1 \mathrm{a}, 1 \mathrm{~b}$ y $1 \mathrm{c}$ ) (5).

La principal razón por la que no se podría otorgar una paternidad directa del planteamiento de De L'Orme hacia las cúpulas y bóvedas encamonadas castellanas no radica tanto en el corte de las piezas de los camones, dado que el sistema francés le dotaba de extradós e intradós mientras el español solo de intradós o extradós dependiendo si era para una bóveda o una cúpula, si no en la concepción estructural del propio sistema. Es decir, las cúpulas encamonadas levantadas en Castilla se realizaron sin pretender llevar una función estructural preponderante, porque los arcos de madera se fijaban sobre una armadura oculta en el intradós o en el caso de las bóvedas encamonadas sujetadas de una estructura más elevada. Mientras la propuesta de De L'Orme daba como consecuencia una cúpula o bóveda autoportante, cuyos diversos elementos se trababan a presión entre sí mediante clavijas de madera, evitando el uso de clavos de hierro (Figura 2).

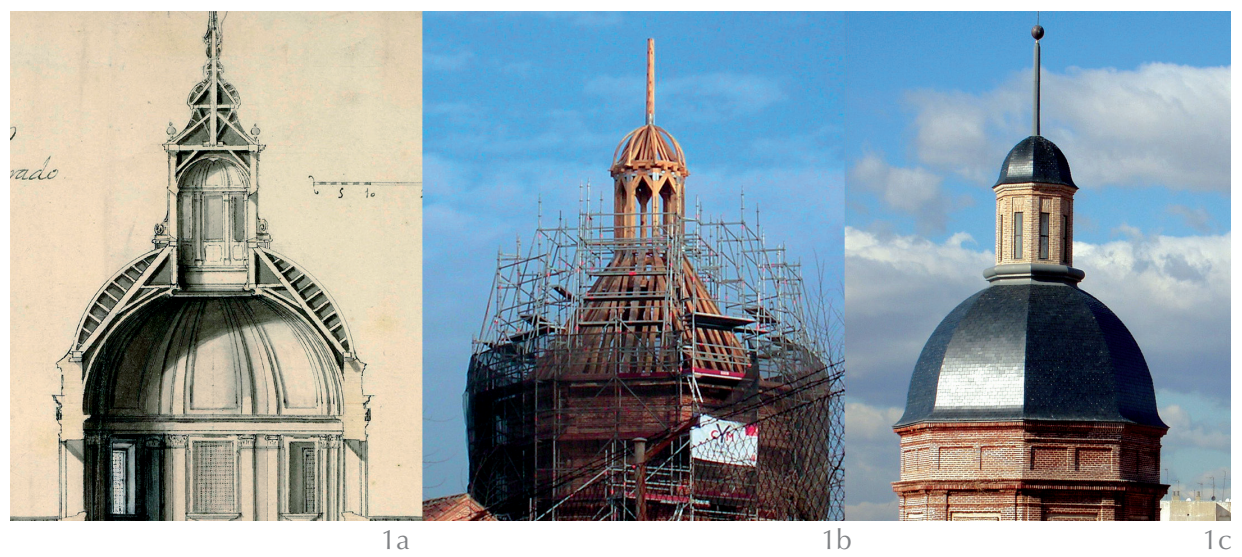


Esta apreciación la confirma el murciano Rejón de Silva (1788), quien mencionaba en su diccionario que una bóveda encamonada se encontraba fijada a la estructura del forjado o cubierta (6).

Una importante condición para que este tipo de armadura apareciera y se difundiera en la región no fue tanto la novedad de la propuesta sino la necesidad de disminuir los costos de las construcciones en general. Esta situación venía motivada por una asfixiante recesión y una progresiva disminución de recursos económicos que sufría la Monarquía española, especialmente durante el siglo XVII (7). Debido a que en aquella época el costo de una bóveda de cantería era cuatro veces superior al de una bóveda encamonada se entiende la razón del auge de este tipo constructivo.

A la austeridad económica imperante se sumó el cambio de estilo arquitectónico con el advenimiento del periodo Barroco y mutuamente consolidaron el empleo de las bóvedas encamonadas. Así los arquitectos se vieron en la obligación de imaginar métodos baratos para la transformación espacial de los templos. Esta solución permitió a muchas iglesias castellanas, que hasta entonces presentaban cubiertas de madera en par y nudillo o pares con tirantes, evitar el desmontaje de la vieja estructura para levantar una nueva, sino que utilizando los elementos de la armadura antigua podían suspender de ella una bóveda encamonada. Por ejemplo en la iglesia de Torrija en Guadalajara la talla en las ménsulas bajo las vigas madres, que actualmente permanecen ocultas detrás de las bóvedas encamonadas, hacen pensar que inicialmente estaban expuestas a la vista.

\section{CARACTERÍSTICAS CONSTRUCTIVAS}

Fray Lorenzo de San Nicolás en la primera parte de su "Arte y Uso de la Arquitectura" explicó brevemente la manera de realizar una bóveda encamonada (Figura 3). Su descripción se ajusta a la tradición constructiva castellana del siglo XVII:

"... hazer alguna bobeda rebaxada, y esta unas vezes se haze encamonada haziendo camones de madera, que son unos pedaços de viguetas, ò tablones...y por el exemplo precedente lo entenderas mejor, aunque no es la misma traça. Supongo, que en el hueco.A.B. quieres hazer la bobeda rebaxada.A.C.B. y que es su suelo de madera.M.N. clava en el suelo de parte a parte dos ristreles con buenos clavos, en el lugar que demuettra .S. T. despues a cada madero echa las çancas o tornapuntas .P.Q.L.V. y desde el asiento de
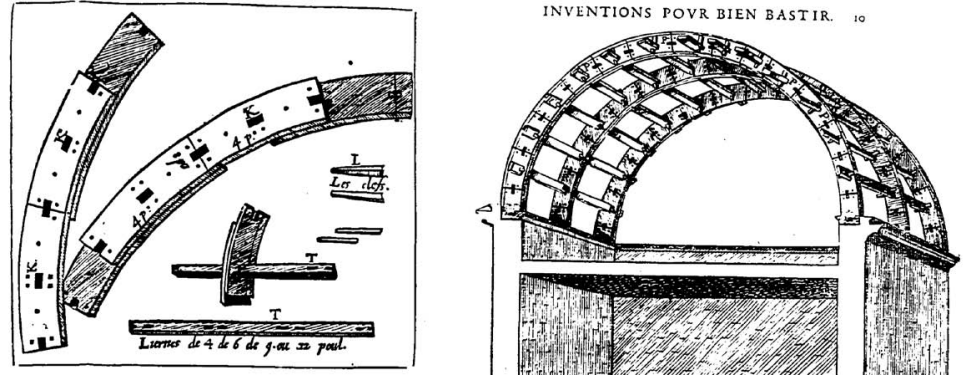

$\mathrm{M}_{4}$

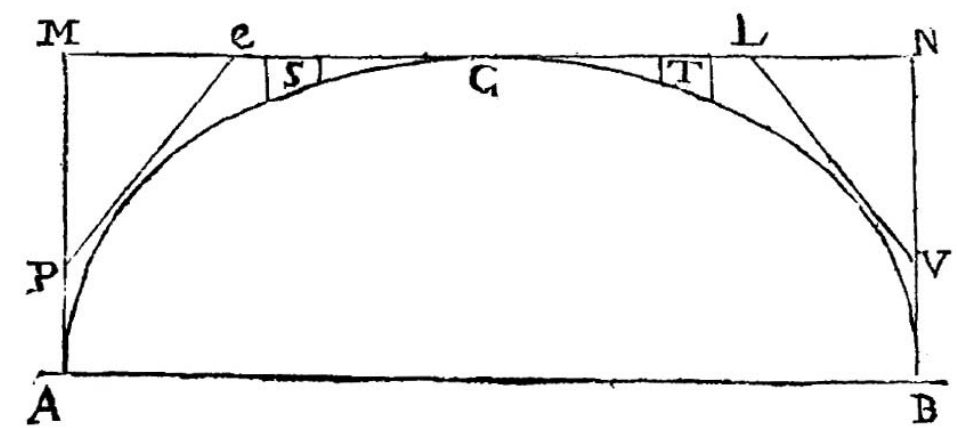

la bobeda .A.B. vè tabicando de sencillo hasta los ristreles; y lo que ay de uno a otro ristrel entre madero y madero, passaràs el tabicado de bobeda, y lo demas del suelo bien entomiçado, jaharraràs segun queda dicho en el cap. 50. y quedara como el deseño lo demuestra... Si fuere encamonada, sentaràs los camones en el lugar que estàn las çancas, ò tornapuntas, con la parte de buelta que les toca" (8).

Según esta descripción San Nicolás indica que una bóveda encamonada debía de suspenderse necesariamente de las vigas del forjado ("suelo" MN), en donde se dispondrían dos viguetas en el sentido longitudinal ("ristreles" S y T) y éstas se conectarían con los jabalcones ("zancas" PQ y LV) de las vigas. A continuación las cerchas confeccionadas con camones se colocarían desde un durmiente de madera definiendo el arranque de la bóveda ("asiento de la bóveda" A.B), debiendo tomar contacto con los jabalcones, las viguetas longitudinales y la parte media de la viga de forjado. Estas bóvedas se podían tabicar con ladrillos en la zona del arranque dejando las piezas de madera anudadas con esparto para luego ser recubierto con yeso ("bien entomizado, jaharrarás").

La transmisión de la técnica constructiva se difundió no sólo por los textos de arquitectura sino también por imitación de las bóvedas ya levantadas, como fue el caso de la bóveda encamonada de la capilla mayor de la iglesia Nuestra Señora de la Cruz, en Cubas de la Sagra (hoy perdida), que fue terminada en 1666 por Manuel García, a imitación de la capilla de San Diego en Alcalá de Henares (9). Al respecto parece
2. Detalles constructivos de las bóvedas encamonadas propuestas por De L'Orme.

3. Elementos que conforman una bóveda encamonada según San Nicolás. 


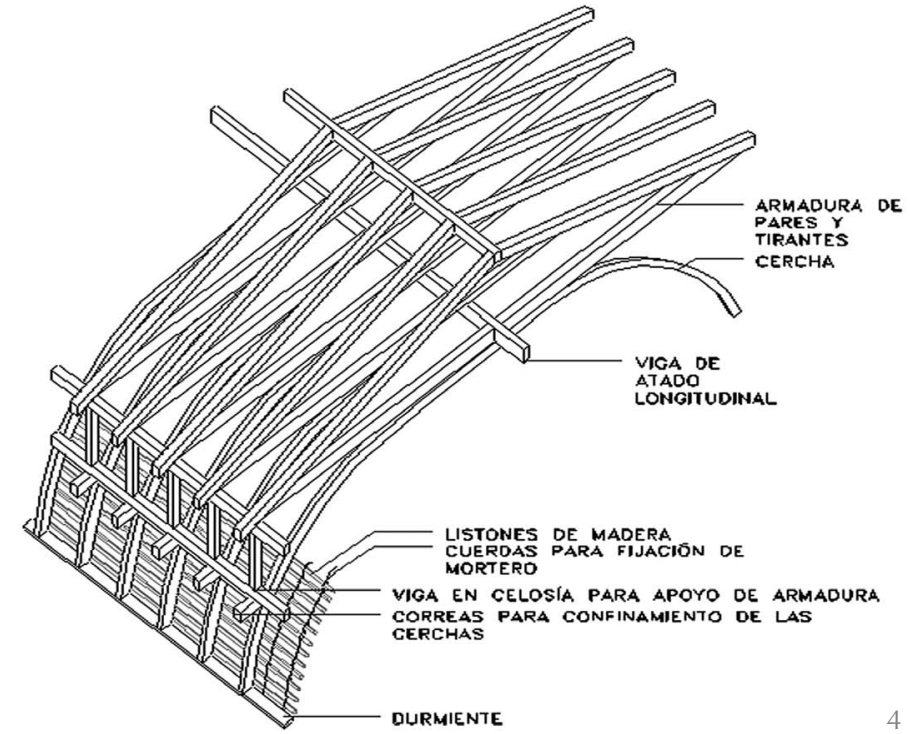

4. Bóveda encamonada del Casón del Buen Retiro.

5. Bóveda encamonada en la biblioteca del colegio de Caracciolos en Alcalá de Henares.

6. Bóveda y cúpula encamonada sobre la escalera principal del colegio de Caracciolos en Alcalá de Henares

Bóveda encamonada en la iglesia de San Antón en Madrid.
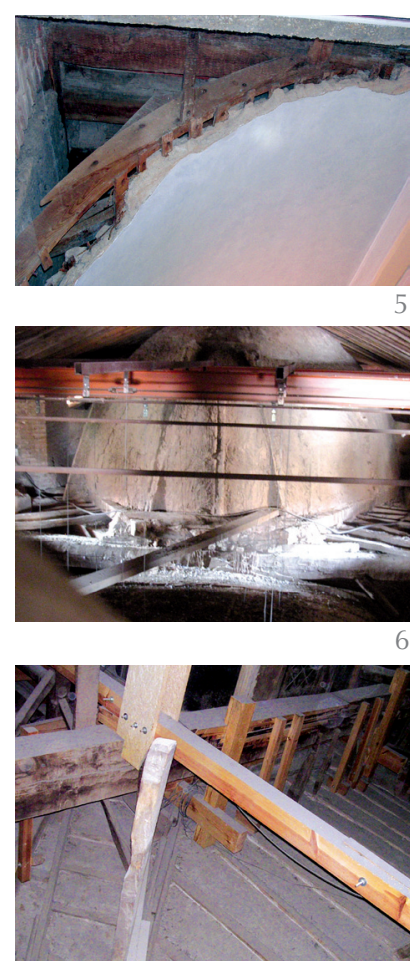

que la villa de Alcalá de Henares constituyó un foco de edificaciones con bóvedas encamonadas, muchas de ellas todavía presentes en el Oratorio de San Felipe Neri y en los colegios de Trinitarios, de Málaga, de Carmen Calzado y de Caracciolos.

La bóveda encamonada del salón de Embajadores en el Casón del Buen Retiro en Madrid, elaborada por Alonso de Carbonell en 1637, se compone de arcos sujetos a una armadura superior de par e hilera y arriostrados por tirantes (Figura 4). Esta armadura presenta además un arriostre longitudinal por medio de una viga de atado que conecta la parte central de los tirantes. Precisamente los arcos de la bóveda cuelgan de dichos tirantes en la zona de la clave, mientras que los arranques se apoyan en un durmiente que recorre los muros. Entre los arcos se clavaron listones de madera por la zona del intradós y luego se colocaron cuerdas que pasaban entre estos listones, los cuales sirvieron para fijar el mortero de yeso y la posterior base pictórica para la ejecución del fresco con el que Luca Giordano dio por finalizada la obra en 1697.

En la actual biblioteca de Caracciolos en Alcalá de Henares los arcos de la bóveda están formados por camones y contracamones clavados entre sí, sin recortar la curva del extradós y sujeta por medio de listones a las vigas de madera que definen la estructura portante en la parte alta (Figura 5). Las vigas se apoyan también sobre unos jabalcones que le permiten reducir la luz libre y al mismo tiempo ayudan a fijar los arcos. El empleo de jabalcones como parte de la estructura de sustento también lo encontramos en las bóvedas sobre la escalera principal del colegio de Caracciolos y en las cúpulas de las capillas del colegio de Carmen Calzado, constituyendo un elemento muy recurrente en las bóvedas encamona- das castellanas. Bajo las cerchas se han clavado listones de madera separados entre sí aproximadamente cinco centímetros, que facilita la fijación del yeso que revoca el intradós de la bóveda.

A diferencia de las bóvedas que podían colgarse de vigas horizontales o inclinadas, según se tratase de un forjado o de una cubierta, las cúpulas normalmente se suspendían de los pares de la armadura de cubierta a las cuales iban clavadas los arcos, como se observa en la cúpula encamonada de la escalera principal del colegio de Caracciolos en Alcalá de Henares y en la reconstrucción de la cúpula de la iglesia de San Agustín en Talavera La Reina (Figura 6).

En la iglesia de San Antón en Madrid, levantada a partir de 1740 por Pedro de Ribera, se ha observado que todas las bóvedas están sostenidas por medio de listones de los tirantes de la armadura de la cubierta, que son las que realizan la labor portante (Figura 7). Entre los arcos se han colocado listones que arman el conjunto y sirven de base al recubrimiento final de yeso. La cúpula de esta iglesia está confeccionada con arcos a base de camones con uniones a media caja, mientras que el cupulín de remate reproduce a una escala reducida el trabajo de los arcos mayores, con recorte del perfil curvo sólo por el intradós. Este caso constituye un modelo interesante de sustento de cúpulas encamonadas, ya que no sólo se encontraban clavadas a los pares de la armadura de cubierta, sino que se recurrió al empleo de cuerdas para atar la clave de la cúpula con la pieza que hacía de hilera en la armadura.

De igual manera la iglesia parroquial de Torija en Guadalajara presenta una bóveda encamonada sujeta de dobles vigas de madera que salvan la luz de la nave y que constituyen los elementos estructurales del conjunto, las cuales aparecen en correspondencia con los arcos fajones que se observan desde el intradós (Figura 8). Sobre estas vigas madres se apoyan seis correas dispuestas en el sentido de la nave, y a un lado de ellas van clavados listones de madera. Son precisamente estos listones los que ayudan a fijar la posición de los arcos mediante un empalme por muesca (10). Finalmente el cerramiento de la bóveda de Torija viene dado por un entablado clavado a los arcos desde el intradós. Al igual que en la capilla de Caracciolos y en la iglesia de San Antón, aquí también las tablas están convenientemente distanciadas entre ellas y rodeadas con cordeles para permitir una mayor adherencia del revoco de yeso con la que eran recubiertas. 
Pero no solo los edificios religiosos acudieron al empleo de las bóvedas encamonadas sino que también fue un recurso habitual en la arquitectura civil y militar. De este modo los alarifes cubrieron grandes salones de palacios, salas de teatro y cuarteles con este sistema constructivo. Por ejemplo el teatro Rojas en Toledo, muestra una concepción constructiva parecida a los casos precedentes, con gruesas vigas horizontales que definen la estructura portante de las que se sujetan los arcos de la bóveda por medio de listones (Figura 9). Como es de esperar también aquí estos arcos se forman con camones y contracamones dotados de perfil curvo únicamente por el lado que viene expuesto.

Entre 1695 y 1703 Teodoro Ardemans realizó trabajos en el Ayuntamiento de Toledo, dentro del cual planteó cubrir la escalera principal con una bóveda encamonada. Según se aprecia en la traza que dejó, la bóveda encamonada se sujetaba de las vigas del forjado y de los jabalcones (11).

En 1775 Francisco Sabatini ejecutó en las galerías del Cuartel para las Reales Guardias Walonas de Leganés unas bóvedas encamonadas de cañón, similares a las anteriormente descritas pero incorporando un cerramiento de cañizo. Parece que Sabatini no estuvo muy complacido con esta solución porque en la memoria de 1761 sobre las condiciones establecidas para la construcción de la Real Aduana de Madrid optó nuevamente por cerrar las bóvedas encamonadas con listones de madera y cordeles, para ayudar a la formación del intradós con yeso. Esta bóveda debía de estar sujetada de un forjado compuesto por vigas de pie y cuarto $(35 \mathrm{~cm})$ y de tercia $(28 \mathrm{~cm})$ separadas cada $50 \mathrm{~cm}$ entre ellas (12).

\section{ELEMENTOS DE UNA BÓVEDA ENCAMONADA}

De acuerdo con los casos observados se puede precisar que las características constructivas de las bóvedas encamonadas, seguían un patrón recurrente bajo el siguiente esquema:

- Durmiente: Actuaba como el elemento de confinación al muro transmitiendo el peso de la armadura, sobre los cuales se apoyaban las vigas madres de un forjado o los pares de una cubierta.

- Vigas o tirantes: Constituyen los principales elementos estructurales del sistema de bóveda encamonada según el procedimiento constructivo castellano. En el caso de un forjado los elementos sustentantes eran las vigas mientras que en una cubierta lo efectuaban los pares o los tirantes. Estos elementos servían además para el apoyo de las correas laterales que conectaban los listones a los arcos.

- Jabalcones: Eran también elementos estructurales muy empleados colocados entre el muro y las vigas, sirviendo como parte del soporte de éstas, en cuanto las ayudaban a reducir la luz libre. Realizaban además una gran labor de fijación de la posición de los arcos, los cuales se colocaban en número igual a los jabalcones y eran clavados lateralmente a ellos.

- Correas: Viguetas de madera dispuestas longitudinalmente en el sentido de la nave de la iglesia y lateralmente a los arcos. Estas correas se apoyaban sobre las vigas principales y se acostumbraba colgar de ellas los arcos por medio de listones.

- Arcos: Formados mayormente por una línea de camones y otra de contracamones, de 3 dedos de espesor. Estas piezas eran colocadas contrapeadas por su cara y unidas mediante clavos para reproducir la curvatura del arco que se necesitaba. Era práctica habitual dejar al camón con el perfil del extradós sin recortar, salvo que se tratase de una cúpula. La lógica constructiva prescindía del recorte del camón para evitar debilitar la sección en la dirección de las fibras, permitiendo que éstas llegaran de un extremo al otro de la pieza.

- Listones de sujeción: Piezas de madera colocadas verticalmente que enlazaban los arcos con las correas y las vigas mediante clavos.

- Enlistonado: Constituía el elemento de cerramiento. Entre los arcos se podían colocar listones de madera, generalmente de un dedo de espesor y separadas entre ellas dos pulgadas. Se rodeaban con cuerdas de esparto para mejorar la fijación del revoco de yeso, que otorgaba el aspecto final al intradós de la bóveda. El modo de fijar el yeso a la madera había conocido algunas variaciones, puesto que inicialmente se hacía picando pequeñas concavidades en las tablas, pero luego se optó por dejar un espacio entre los listones que permitiera al revoco envolver $y$ formar cuerpo de manera conjunta con la madera. El empleo de los listones como elemento de base para recibir el revoco de yeso la había referido ya San Nicolás en el siglo XVII y Bails en 1802 incluía en su diccionario el verbo "enlistonar" como sinónimo de "poner listones para labrar una bóveda encamonada..." (13).

- Encañado: Cuando no se empleaban listones de madera para cerrar la bóveda se reemplazaban éstos por un tejido elaborado con cañas partidas y extendidas longitudinalmente, las cuales venían clavadas bajo las correas y los arcos para formar una superficie rugosa adecuada a recibir el revoco de yeso del intradós (Figura 10).
8. Bóveda encamonada en iglesia de Torija en Guadalajara.

9. Bóveda encamonada en el teatro Rojas en Toledo.

10. Bóveda encamonada en la iglesia de San Agustín en Talavera la Reina.

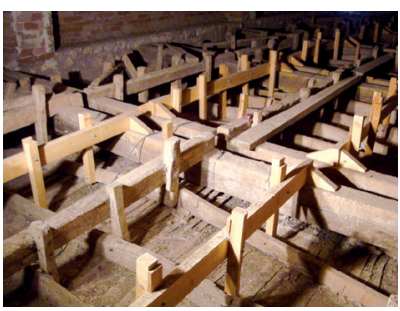

8
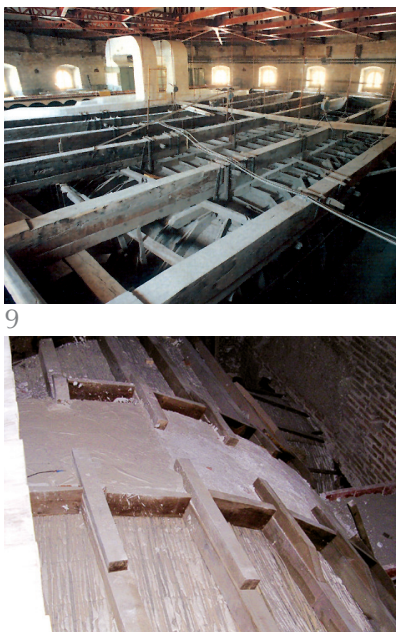

10 
- Tabicado: Particularmente excepcional se mostró la ejecución de híbridos de cúpulas encamonadas con cerramiento de fábrica. Este sistema se conformaba con arcos de madera que definían el contorno estructural del domo mientras que los vacíos eran tabicados hasta un tercio de su altura con ladrillos, incorporando en el resto tablas con cordeles alrededor de ellas para la fijación del yeso por el intradós.

\section{CONSIDERACIONES ESTRUCTURALES SOBRE LAS BÓVEDAS ENCAMONADAS}

Si bien Leonardo da Vinci en el siglo XV había esbozado un arco de madera compuesto por piezas con empalmes en diente de sierra y clavijas metálicas, no llegaría a realizar ningún análisis de la capacidad mecánica de este arco (14). El conocimiento científico sobre el desempeño de la madera aún no se encontraba suficientemente desarrollado cuando Philibert De L'Orme elaboró sus bóvedas encamonadas. El arquitecto galo tuvo que realizar ensayos públicos ante el escepticismo de miembros de la corte francesa, sin pretender extraer más conclusiones que la simple verificación visual de la capacidad de carga y de la estabilidad general de su propuesta. De L'Orme pensaba que en una estructura conformada por muchas piezas, solidarias entre sí mediante múltiples ensambles, la distribución de los esfuerzos era uniforme. De este modo se garantizaba mayor estabilidad, debido a que si fallaba una parte de las piezas el resto se ajustaría a la nueva configuración.

No se tienen noticias coetáneas a De L'Orme de la realización de ensayos para verificar el comportamiento de las estructuras encamonadas. Por otro lado en España la experiencia constructiva acumulada en el siglo siguiente habría demostrado la fiabilidad estática de estas bóvedas al ser sometidas a cargas verticales.

Los estudios para determinar las características de este tipo de construcción quedaron estancados, particularmente en Francia durante dos siglos, hasta que la importancia otorgada al entrenamiento continuado de la caballería militar, hizo indispensable contar con naves de grandes luces sin apoyos intermedios. Esta situación alentó a los ingenieros franceses a revisar textos antiguos que tratasen al respecto y que permitió redescubrir los planteamientos de De L'Orme. Como consecuencia de una renovada aproximación a las estructuras encamonadas, éstas se plasmaron también en la arquitectura civil. Así en 1782 Guillaume Legrand y Jacques Molinos, siguiendo los postulados de De L'Orme, levantaron la cúpula de Halle au Blé en Paris. Posteriormente Joseph Chalgin y G. Detournelle, continuaron con esta tendencia para la construcción de las amplias salas de la cervecería de Rennes y en el Senarmom de Fontainebleau en 1799 y 1800 respectivamente.

En este punto los ingenieros franceses se toparon con interrogantes claves sobre si las leyes tradicionales de proporción de las bóvedas de fábrica eran válidas para las bóvedas de madera, si la transmisión de cargas a través de las múltiples uniones seguía el principio de los arcos de fábrica, si el comportamiento de una estructura ligera de madera podía asimilarse a una pesada de fábrica, y si las consideraciones elásticas afectaban ambas estructuras en la misma dirección. Todas estas cuestiones quedaron sin ser esclarecidas completamente debido a la posterior preferencia por el empleo de los arcos de madera que había ideado Armand Emy (tablas superpuestas por el canto, unidas con cinchos metálicos) y luego por el desarrollo de las estructuras de acero.

Contemporáneamente en Prusia y Sajonia aparecieron publicaciones sobre el sistema encamonado de De L'Orme, tratando de analizar su comportamiento estructural. David Gilly, jefe de la oficina de construcciones de Prusia, publicó en 1797 su texto "Sobre la invención, construcción y ventajas de las cubiertas conformadas con planchas de madera" en la cual evaluaba el comportamiento de los arcos encamonados, considerando que éstos seguían el mismo principio de los de fábrica y como tal explicaba su preferencia por los arcos apuntados (15). Para su estudio empleó las proporciones de los camones de De L'Orme $(2,5 \times 30 \mathrm{~cm})$, aunque al final criticó el uso de correas pasantes por el centro de los camones, como proponía De L'Orme. Gilly argumentaba que este tipo de listón pasante debilitaba al arco y recomendaba que a tal efecto el canto mínimo de un camón debiera tener $25 \mathrm{~cm}$, con un espesor mayor a los $2,5 \mathrm{~cm}$.

Similarmente Johann Albert Eytelwein (17641848) asumía las juntas de los camones como conexiones rígidas, especulando que la transmisión de los esfuerzos en compresión en los arcos encamonados eran de la misma entidad que el producido en los arcos de fábrica y que las deformaciones elásticas observadas eran solo el resultado de la presión efectuada. Por su parte Franz Joseph Ritter von Gerstner (1756-1832) trabajó sobre el análisis de la capacidad de carga de los arcos encamonados, pero desde la perspectiva de su aplicación a puentes. Dichos arcos se ensamblaban tratando de seguir una imaginaria línea de empujes, con una preocupación centrada en la transmisión de los esfuerzos a compresión (16). 
Mención importante merecen los trabajos de Zimmermann (1830) y Paul Joseph Ardant (1847), quienes experimentaron con modelos de arcos encamonados sometiéndolos a cargas en su contorno curvo, para lo cual utilizaron cuerdas y poleas que se ajustaban al perímetro exterior de dichos arcos. Ardant aplicó a los arcos los estudios de Navier sobre el comportamiento elástico de los materiales y observó que estas estructuras mostraban una pérdida importante de rigidez debido al sistema de conexión. Una de las conclusiones de los ensayos fue que la estructura tendía a girar en las uniones entre camones, hundiéndose en la clave y elevándose en la zona de los arranques, fallando no por cortante perpendicular a la fibra sino por cizallamiento en la dirección de la fibra, justamente en la posición de los clavos (Figura 11).

A pesar de estas pruebas, las consideraciones propias de los arcos de fábrica, como la forma ideal y las resultantes de las reacciones siguieron dominando la discusión científica sobre los arcos encamonados hasta mediados del siglo XIX. Se debe recordar que en aquel momento se tenían dos acercamientos al análisis de arcos de fábrica basados en e equilibrio y en el punto de ruptura. La teoría del equilibrio, según la cual la transmisión de los esfuerzos a compresión dentro de una bóveda de fábrica sigue el perfil de una catenaria invertida, planteaba la necesidad de conocer la forma adecuada del arco. La segunda manifestaba que lo importante no era buscar la forma ideal del arco sino la obtención de los empujes para calcular el ancho de los estribos necesarios para contener dichos empujes (17). La novedad del concepto de línea de empujes, apareció simultáneamente en Inglaterra (Moseley, 1835) y Francia (Méry, 1840) e impulsó a plantearlos también a los arcos de madera. Para 1850 Johann Andreas Romberg aún recomendaba construir arcos encamonados siguiendo la forma de una catenaria invertida.

En la realidad estas estructuras de madera no trabajan únicamente a compresión como los arcos de fábrica sino que por la naturaleza del material son capaces de admitir esfuerzos a flexión, además que el sistema constructivo posee mayor ductilidad (18).

A diferencia del sistema en arco, que es propio de las bóvedas de De L'Orme, el sistema en viga constituyó la experiencia básica del empleo de bóvedas encamonadas en Castilla. Como se ha mencionado anteriormente, este sistema constructivo se caracteriza porque los arcos están sostenidos por otra armadura, ya sea las vigas horizontales que conforman un forjado o los pares o tirantes de una cubierta. Por el modo de su

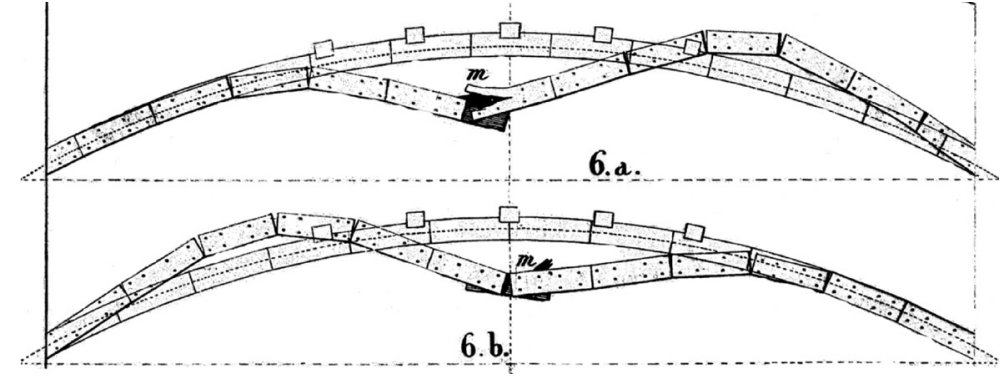

11

disposición en el conjunto de la estructura se observa que los arcos no colaboran en la descarga del peso de los forjados ni generan empujes laterales a los muros, porque vienen utilizados únicamente para definir espacialmente el ambiente a cubrir.

El sistema en viga contempla dos subtipos. El primero se refiere a bóvedas con sus arcos colgados de las vigas del forjado mediante listones, y representa el más puro estilo castellano. El segundo subtipo constituye el de las bóvedas unidas a las vigas, en donde no se hace empleo de los listones, sino que los arcos se clavan directamente a las vigas y a los jabalcones de la armadura. Este tipo de bóveda se difundió además en Hispanoamérica y en los virreinatos españoles de Nápoles y de las Filipinas. En el Virreinato de Perú se introdujo el sistema con la consideración de ser más estables frente a los sismos que las bóvedas de fábrica, especialmente después de la reconstrucción de las bóvedas de la catedral de Lima en 1688 (19).

En apariencia las bóvedas en sistema en viga al no tener un comportamiento estructural predominante no acusan mayor problema que el del peso propio y mantenimiento de su forma. Sin embargo dado que dependen de una estructura superior de la que están suspendidas cualquier cambio en la configuración de éstas tendrá una repercusión en la bóveda. El principal problema radica en que con el paso del tiempo y el estado de conservación de la estructura portante, ésta puede sufrir flechas con el correspondiente desplazamiento que se transmitirán a los listones de sujeción. En este caso los listones pasarán de ser elementos trabajando a tracción, como sostén de la bóveda desde las vigas, a piezas trabajando a compresión. Así se producirá una concentración de esfuerzos en el arco justamente en las zonas correspondientes a la deformación de la viga madre.

\section{CONCLUSIÓN}

Las bóvedas encamonadas constituyen un patrimonio arquitectónico de notable presencia en tierras castellanas, merecedoras de un mayor conocimiento de sus características constructivas y comporta- 
miento estructural. Aunque las raíces de las bóvedas encamonadas se encuentran en Philibert De L'Orme, las bóvedas que aparecieron en Castilla obedecieron a una solución en la que la bóveda no necesitaba ser autoportante como el caso francés, porque siempre estaba sujeta de una armadura superior. Es precisamente este tipo de bóveda la que luego se exportaría a las colonias españolas en América.

Se puede decir que los primeros estudios estructurales sobre bóvedas encamonadas empezaron en el siglo XIX, de modo contemporáneo en Francia y Alemania. En un inicio asemejando el comportamiento de las bóvedas de fábrica a las encamonadas para luego observar la particular importancia de las uniones, principalmente con los trabajos de Zimmermann. Sin embargo la pronta aparición de otras alternativas para cubrir grandes luces como fueron las estructuras de acero significó la ruptura con toda esta tradición constructiva y con el interés por comprender su funcionamiento estructural.

\section{REFERENCIAS}

(1) De L'orme, P. Traités d'architecture: Nouvelles Inventions pour bien bastir et à petits fraiz. Premier Tome de l'Architecture. p. 5a, Paris, 1561 (facs. Ed. Paris : Léonce Laget, Libraire-Èditeur, 1988).

(2) Torija, J. (1661). Breve Tratado de todo Género de bobedas. Así Regulares como yrregulares execucion de obrarlas y Medirlas con singularidad y Modo Moderno observando los preceptos Canteriles de los Maestros de Architectura. pp. 73-75, Pablo de Val, Madrid.

(3) Marias, F. (1987). Sobre un dibujo de Juan de Herrera, de El Escorial a Toledo. Real Monasterio Palacio de El Escorial, estudios inéditos en el IV centenario de la terminación de las obras. pp. 167-177, Consejo Superior de Investigaciones Científicas Departamento de Arte Diego Velásquez del Centro de Estudios Históricos, Madrid.

(4) San Nicolás, F. L. Arte y Uso de Arquitectura, segunda parte. Cap. 51, p. 189, Madrid, 1639 (facs. Ed. Madrid: Albatros, 1989).

(5) Hurtado Valdez, P. (2009). Las bóvedas de madera en los tratados de arquitectura. Bia, 260: 99-114, Colegio Oficial de Aparejadores y Arquitectos Técnicos de Madrid, Madrid.

(6) Nuere Matauco, E. (2000). La carpintería de armar española. p. 288, Editorial Munilla Lería, Madrid.

(7) Corella Suarez, M. P. (1979). Arquitectura religiosa de los siglos XVII y XVIII en la provincia de Madrid. Estudio y documentación del partido judicial de Getafe, Madrid. Consejo Superior de Investigaciones Científicas, Instituto de Estudios Madrileños.

(8) San Nicolás, F. L.(1667). Arte y Uso de Arquitectura, primera parte. Cap. 52, pp. 91-92, Madrid.

(9) Archivo Historico de Protocolos de Madrid, Protocolo 7386, f.597-602, año 1666. Escritura publica entre Manuel García y fray Juan de San Francisco para los trabajos en el convento de Nuestra Señora de la Cruz en Cubas de la Sagra.

(10) Villanueva Dominguez, L. (2005). Bóvedas de madera. Actas del Cuarto Congreso Nacional de Historia de la Construcción, 2: 1103-1113, Instituto Juan de Herrera, Madrid.

(11) Díaz Fernández, A. J. (1993). Teodoro Ardemans en la obra del Ayuntamiento de Toledo (1695-1703). Espacio, Tiempo y Forma, Serie VII, Historia del Arte, 6: 275-310. UNED, Facultad de Geografía e Historia.

(12) Sabatini, F. (1761). Condiciones y Methodo para executar por assiento la Real Obra de Aduana, Directoria de Tabacos y Rentas Generales y Provinciales, que se va a construir de orden de S.M. en la calle de Alcalá de esta Corte. Madrid.

(13) Bails, B. (1802). Diccionario de Arquitectura Civil. p. 39, Madrid. Imprenta de la Viuda de D. Joaquin Ibarra.

(14) Timoshenko, S. P. (1983). History of strength of materials. pp. 3-6, New Cork. Dover Publications, Inc.

(15) Gilly, D. Ueber Erfindung, Construction und Vortheile der Bohlen-Dächer mit besonderer Rücksicht auf die Urschrift ihres Erfinders. Friedrich Vieweg d. Ä., Berlin. 1797.

(16) Hahmann, L. (2006). How stiff is a curved timber plank? Historical discussions about curved-plank structures. Proceedings of the Second International Congress on Construction History, 2: 1501-1516. Cambridge: Malcom Dunkeld, James Campbell, Hentie Louw, Michael Tutton, Bill Addis y Robert Thorne, ed.

(17) Huerta Fernández, S. (2004). Geometría y equilibrio en el cálculo tradicional de estructuras de fábrica, Madrid. Instituto Juan de Herrera.

(18) Heyman, J. (2006). Timber Vaults. Proceedings of the Second International Congress on Construction History, 2: 1569-1577. Malcom Dunkeld, James Campbell, Hentie Louw, Michael Tutton, Bill Addis y Robert Thorne, ed., Cambridge.

(19) Hurtado Valdez, P. (2009). Masonry or wooden vaults?: the technical discussion to rebuilt the vaults of the cathedral of Lima in the seventeenth century. Proceedings of the Third International Congress on Construction History: 845-852, Brandenburg University of Technology, Cottbus. 